\title{
Evaluasi Tata Kelola Teknologi Informasi Menggunakan Kerangka Kerja Cobit 5 di Gelato Secrets
}

\author{
Ayu Manik Dirgayusari*, Desak Made Dwi Utami Putra **, Ni Wayan Rika Andini*** \\ * Sistem Komputer, STMIK STIKOM Indonesia \\ ** Teknik Informatika, STMIK STIKOM Indonesia \\ *** Teknik Informatika, STMIK STIKOM Indonesia \\ *ayu.manik@stiki-indonesia.ac.id, **desak.utami@stiki-indonesia.ac.id,*** rikaandini2105@gmail.com
}

\begin{abstract}
Many people have benefited from the use of information technology, one of which is in the trade business sector. One company that is engaged in manufacture that utilizes information technology in its operational processes is Gelato Secrets. Its efforts to support business goals have been supported by an Information System (SI) which is still relatively new to be implemented in Gelato Secrets, namely the Odoo application that supports the sales process in each outlet. To evaluate the maturity level of information technology governance in the Odoo application, a framework is needed as a reference model to ensure the quality of IT governance in the application of the "Odoo" application. Control Objective for Information and related Technology (COBIT) is a best practice that provides an organization's entire business process and describes it in a logical structure of activities that can be managed and controlled effectively. The results of the research, measuring the average level of capability obtained, have only reached the Established Process level, which means that each sub-domain has been well defined and standardized. This shows that almost all processes meet the requirements, but there are still weaknesses on the side of system changes caused by the absence of an adequate documentation process. The company still has to fulfill the level 5 process, namely Optimizing Process by means of regular training to HR about existing Information Systems and also fulfilling user needs such as adding menus that can facilitate the smooth running of business processes in order to meet the expected company targets, as well as adding more technology devices. Information needed by the company in sufficient quantities.
\end{abstract}

Keyword: Information Technology, Governance, COBIT

\begin{abstract}
ABSTRAK
Pemanfaatan bidang teknologi informasi saat ini sudah banyak yang merasakan manfaatnya salah satunya yaitu pada bidang bisnis perdagangan. Salah satu perusahaan yang bergerak dalam bidang manufacture yang memanfaatkan teknologi informasi dalam proses operasionalnya adalah Gelato Secrets. Usahanya dalam menunjang tujuan bisnis telah didukung oleh Sistem Informasi (SI) yang masih tergolong baru diimplementasikan di Gelato Secrets yaitu aplikasi Odoo yang mendukung proses penjualan disetiap outlet. Untuk mengevaluasi tingkat kematangan tata kelola teknologi informasi dalam aplikasi Odoo diperlukan suatu kerangka kerangka kerja sebagai reference model, untuk memastikan kualitas tata kelola TI pada penerapan aplikasi "Odoo". Control Objective for Information and related Technology (COBIT) merupakan sebuah best practice yang menyediakan keseluruhan proses bisnis organisasi dan memaparkannya dalam struktur aktivitas-aktivitas logis yang dapat dikelola dan dikendalikan secara efektif. Hasil dari penelitian pengukuran rata-rata tingkat kapabilitas yang didapat baru mencapai level Established Process yang artinya setiap sub domain sudah terdefinisi dan terstandarisasi dengan baik. Hal ini menunjukkan hampir semua proses memenuhi syarat, akan tetapi masih tedapat kelemahan pada sisi perubahan sistem yang disebabkan oleh tidak adanya proses dokumentasi yang memadai. Perusahaan masih harus memenuhi proses level 5 yaitu Optimizing Process dengan cara pelatihan rutin kepada SDM tentang Sistem Informasi yang ada dan juga memenuhi kebutuhan pengguna seperti menambahkan menumenu yang dapat mempermudah kelancaran proses bisnis agar dapat memenuhi target perusahaan yang diharapkan, serta melakukan penambahan perangkat Teknologi Informasi yang dibutuhkan perusahaan dalam jumlah yang memadai.
\end{abstract}

Keyword: Teknologi Informasi, Tata Kelola, COBIT 


\section{Introduction}

Gelato Secrets merupakan sebuah perusahaan manufacture yang pertama kali berkembang di Ubud pada tahun 2009. Gelato secrets memiliki 9 outlet di Bali yang berada di kawasan Ubud, Sanur, Seminyak, Canggu, dan Tanah Lot. Selain di bali, Gelato Secrets juga memiliki 3 outlet di Jakarta yang berada di kawasan Setiabudi, Shophaus Menteng dan juga di Karet Tengsin. Dalam menjalankan proses bisnisnya, Gelato Secrets memanfaatkan teknologi untuk mempermudah dalam setiap proses yang dilakukan yaitu dengan pemanfaatan Teknologi Infomasi (TI). TI dalam organisasi harus selalu diawasi sehingga layanan yang diberikan kepada pengguna dapat maksimal, diantaranya adalah dengan melakukan proses audit untuk mengidentifikasi tingkat kematangan TI sehingga pihak manajemen TI dapat menemukan solusi dari proses yang dirasa kurang maksimal.[1]. Tata Kelola Teknologi Informasi (TI) digunakan untuk membangun suatu sistem yang membantu perusahaan dalam proses pengambilan keputusan dimana melibatkan para pemangku kepentingan dan elemen-elemen terkait dalam perusahaan [2]. Aplikasi yang digunakan saat ini untuk mendukung proses penjualan Gelato Secrets yaitu Odoo. Fitur Odoo yang digunakan di Gelato Secrets yaitu point of sales, inventory dan juga barcode. Odoo yang telah diterapkan pada Gelato Secrets merupakan aplikasi yang menggunakan bahasa pemrograman bahasa python yang dikembangkan oleh komunitas sehingga membuat sistem informasi ini juga lambat dalam operasinya dan sewaktu-waktu akan banyak mengalami perubahan dan perbaikan, sehingga kedepannya akan ada yang tidak sesuai dengan implementasinya. Jika aplikasi ini tidak berjalan sesuai dengan implementasinya maka akan menghasilkan data dan informasi yang salah dan akan mengakibatkan sebuah pengambilan keputusan yang salah pula. Aplikasi ini perlu untuk dievaluasi untuk mengetahui apakah sistem informasi yang diterapkan sudah sesuai dengan tujuan perusahaan. Berdasarkan permasalahan tersebut perlu dilakukannya Evaluasi terhadap pengelolaan Teknologi Informasi tersebut. Dalam kerangka kerja COBIT 5 dapat memberikan evaluasi terhadap tata kelola Teknologi Informasi, mengetahui tingkat kematangan Teknologi Informasi dan juga dapat memberikan rekomendasi yang digunakan untuk perbaikan pengelolaannya di masa mendatang. COBIT adalah suatu metodologi yang memberikan kerangka dasar dalam menciptakan sebuah TI yang sesuai dengan kebutuhan organisasi [3]. Tujuan COBIT adalah menyediakan model dasar yang memungkinkan pengembangan aturan yang jelas dan praktek yang baik dalam mengontrol informasi dalam sebuah organisasi untuk mencapai tujuannya [4] [5]. Penggunaan metode COBIT 5 dapat memberi manfaat untuk perusahaan agar dapat menangani permasalahan yang terjadi di Gelato Secrets. Pada penelitian ini metode yang yang digunakan difokuskan pada domain Evaluate, Direct, and Monitor (EDM), Align, Plan, and Organize (APO), Build, Aquire, and Implement (BAI), Monitor, Evaluate, and Asses (MEA), Deliver, Service, and Support (DSS). Perbandingan antara COBIT 5 dan COBIT 2019 dapat dilihat dari gambaran umum pada COBIT 5 belum ada faktor desain, sedangkan pada COBIT 2019 telah ditambahkan faktor desain sehingga dapat lebih menyesuaikan dengan perusahaan. Prinsip pada COBIT 5 lebih ringkas sehingga dapat memudahkan juga dalam implementasi sedangkan pada COBIT 2019 lebih banyak dan memungkinkan untuk flexible, domain pada COBIT 5 lebih bersifat proses sedangkan pada COBIT 2019 lebih objektif dan detail domain pada COBIT 2019 yang memiliki beberapa tambahan dan menekankan pada hasil yang dicapai [6]. Pada penelitian ini menggunakan kerangka COBIT 5 karena Gelato Secrets perusahaan dengan skala yang tidak terlalu besar dan lebih menekankan pada setiap proses tata kelola perusahaan untuk mendapatkan rekomendasi perbaikan yang lebih baik.

\section{Research Method}

Tahapan penelitian yang dijalankan pada penelitian ini untuk merumuskan suatu perancanaan strategis SI/TI yang efektif dan mampu meningkatkan kinerja bagi Gelato Secrets. Sedangkan untuk menemukan solusi yang tepat, pada penelitian ini ada beberapa tahapan yang akan dilakukan dapat dilihat pada gambar 1. 


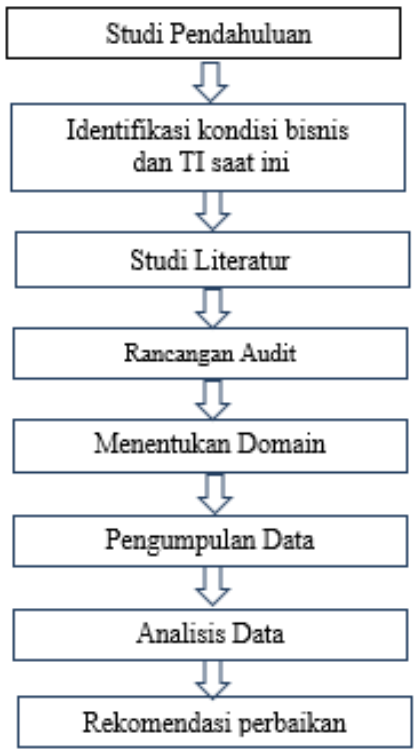

Gambar 1. Tahapan Penelitian

Tahap pertama dalam penelitian ini adalah melakukan studi visi dan misi perusahaan dilanjutkan dengan melakukan observasi dan wawancara dengan bagian tertinggi yang mengatur jalannya manajemen teknologi informasi untuk mengetahui pemasalahan yang dihadapi. Wawancara juga bertujuan untuk mengetahui lebih jelas objek yang dievaluasi sehingga penelitian lebih terarah pada saat dilakukan proses evaluasi. Tahap kedua melakukan analisis terhadap tata kelola TI yang berjalan di Gelato Secrets. Proses analisis tata kelola di lakukan untuk mengidentifikasikan tujuan bisnis dan tujuan TI yang berjalan untuk dapat menentukan kondisi lapangan saat ini. Tahap selanjutnya adalah melakukan studi literatur tentang penelitian yang serupa, yaitu kerangka kerja menggunakan COBIT.

\subsection{Pemetaan Rencana Strategis Gelato Secrets dengan COBIT 5 Enterprise Goals}

Berdasarkan studi literature yang dilakukan, penelitian tersebut didapatkan hasil alur yang harus dikerjakan dan mengindentifikasi domain. Tahapan keempat yaitu Rancangan Audit yaitu pemetaan tujuan bisnis dan tujuan TI Gelato Secrets. Pemetaan mengacu pada panduan pemetaan Enterprise Goals, pemetaan IT-Related Goals dan juga pemetaan proses COBIT 5. Hasil pemetaan Enterprise Goals COBIT 5 yang telah diperoleh proses sebelumnya dengan IT-Related Goals COBIT 5.

\subsection{Pemetaan IT-Related Goals terhadap Proses COBIT 5}

Pemetaan Enterprise Goals bertujuan untuk memadankan tujuan bisnis dan visi misi organisasi dengan Enterprise goals yang ada pada COBIT 5. Pemetaan IT-Related Goals bertujuan untuk melihat keterkaitan antara tujuan bisnis organisasi dari hasil padanan Enterprise Goals dengan IT Related Goals pada COBIT 5 dan pemetaan proses COBIT 5 bertujuan untuk menemukan proses-proses domain yang ada pada COBIT 5 yang dikaitkan dengan IT Related Goals yang telah dipetakan. Untuk menyeleraskan tujuan bisnis dan TI perusahaan berdasarkan standar COBIT 5. Dari pemetaan tersebut, didapatkan domain-domain yang dibutuhkan dalam proses audit. Berdasarkan langkah-langkah proses pemetaan IT-Related Goals maka domain yang akan dipakai dalam melakukan audit teknologi informasi pada Gelato Secrets. Hasil pemetaan dapat dilihat pada tabel 2 .

Tabel 2. Pemetaan COBIT 5 Terpilih

\begin{tabular}{|l|l|}
\hline Domain & \multicolumn{1}{c|}{ Proses COBIT 5 } \\
\hline EDM & EDM01, EDM02, EDM03, EDM04, EDM05 \\
\hline APO & $\begin{array}{l}\text { APO01, APO02, APO03, APO07, APO08, APO09, APO10, } \\
\text { APO11, APO12, APO13 }\end{array}$ \\
\hline BAI & BAI01, BAI02, BAI03, BAI04, BAI05, BAI06, BAI07, BAI10 \\
\hline DSS & DSS01, DSS02, DSS03, DSS04, DSS05, DSS06 \\
\hline MEA & MEA01, MEA02, MEA03 \\
\hline
\end{tabular}

Lalu dilanjutkan dengan pengembangan instrumen pengumpulan data dari domain yang telah dipilih. Tahap keenam adalah tahap pengumpulan data dari pihak - pihak yang terlibat dalam proses bisnis. Data-data inilah yang akan dianalisis dengan maturity level. 


\section{Result and Analysis}

\subsection{Analisis Identifikasi Responden}

Responden yang terlibat dalam penelitian ini berjumlah 4 responden. Responden yang dipilih yaitu responden yang memahami tentang penggunaan aplikasi odoo yang digunakan di Gelato Secrets. Responden diminta untuk memberikan pendapatnya mengenai tingkat kematangan TI yang mengacu pada kerangka kerja COBIT 5.

\subsection{Penilaian dan Perhitungan Kuisioner}

Dalam menentukan kondisi pada level manakah aktifitas - aktifitas yang terdapat pada form kerja audit itu berada, maka dilakukan analisis berupa mencari level yang tepat pada form hasil kuisioner. Penentuan level ditiap aktifitas ini dilakukan dengan memilih nilai modus atau nilai yang paling banyak muncul pada tiap aktifitasnya. Pada penilaian skor (nilai) masing - masing responden, peneliti menentukan setiap jawaban dengan angka yaitu $0,1,2,3,4$, dan 5. Selanjutnya data yang sudah diperoleh melalui data kuisioner tersebut diberikan nilai yang sudah ditentukan.

\subsection{Domain EDM (Evaluate, Direct and Monitor)}

Dari penyebaran kuisioner yang dilakukan untuk menilai Domain EDM, didapatkan rekap hasil kuisioner yang dapat dilihat pada tabel 3.

Tabel 3. Perhitungan Rata - Rata Domain EDM

\begin{tabular}{|c|c|c|c|c|c|}
\hline EDM & Responden 1 & Responden 2 & Responden 3 & Responden 4 & Rata-rata \\
\hline $\mathbf{1}$ & 4 & 3 & 4 & 3 & 3,50 \\
\hline $\mathbf{2}$ & 3 & 3 & 4 & 3 & 3,25 \\
\hline $\mathbf{3}$ & 4 & 2 & 4 & 2 & 3,00 \\
\hline $\mathbf{4}$ & 3 & 3 & 4 & 2 & 3,00 \\
\hline $\mathbf{5}$ & 3 & 3 & 4 & 3 & 3,25 \\
\hline
\end{tabular}
dalam tabel 4.

Tabel 4. Analisa GAP Domain EDM

\begin{tabular}{|c|c|c|c|c|}
\hline No & Pertanyaan & $\begin{array}{l}\text { Current } \\
\text { Maturity }\end{array}$ & $\begin{array}{l}\text { Expected } \\
\text { Maturity }\end{array}$ & $\begin{array}{l}\text { Analisa } \\
\text { Gap }\end{array}$ \\
\hline 1. & $\begin{array}{l}\text { Bagaimana tata kelola teknologi informasi (TI) yang sedang } \\
\text { berjalan di perusahaan ini? }\end{array}$ & 3,50 & 5,00 & 1,50 \\
\hline 2. & $\begin{array}{l}\text { Bagaimana memastikan TI dapat memberikan pemanfaatan } \\
\text { yang optimal? }\end{array}$ & 3,25 & 5,00 & 1,75 \\
\hline 3. & $\begin{array}{l}\text { Menurut anda, bagaimana optimalisasi manajemen risiko } \\
\text { terhadap TI yang digunakan dalam proses bisnis di perusahaan } \\
\text { anda? }\end{array}$ & 3,00 & 5,00 & 2,00 \\
\hline 4. & $\begin{array}{l}\text { Menurut anda, bagaimana cara memastikan optimalisasi } \\
\text { sumber daya TI yang ada di perusahaan anda? }\end{array}$ & 3,00 & 5,00 & 2,00 \\
\hline 5. & $\begin{array}{l}\text { Menurut anda, bagaimana penyampaian informasi kepada } \\
\text { pihak-pihak stakeholder apakah sudah cukup transparan? }\end{array}$ & 3,25 & 5,00 & 1,75 \\
\hline & Rata-rata & 3,2 & 5,00 & \\
\hline
\end{tabular}

Analisa Gap antara Current Maturity dan Expected Maturity ditampilkan melalui grafik yang dapat dilihat pada gambar 2 . 


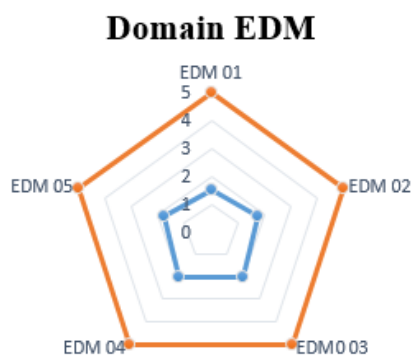

- 0 -Sekarang - - -Target

Gambar 2. Tampilan Grafik Current dan Target Maturity Level Domain EDM

\subsection{Domain APO (Align, Plan and Organize)}

Dari penyebaran kuisioner yang dilakukan untuk menilai Domain APO, didapatkan rekap hasil kuisioner yang dapat dilihat pada tabel 5.

Tabel 5. Perhitungan Rata-Rata Domain APO

\begin{tabular}{|c|c|c|c|c|c|}
\hline APO & Responden 1 & Responden 2 & Responden 3 & Responden 4 & Rata-rata \\
\hline $\mathbf{1}$ & 3 & 3 & 3 & 3 & 3,00 \\
\hline $\mathbf{2}$ & 3 & 4 & 3 & 3 & 3,25 \\
\hline $\mathbf{3}$ & 3 & 2 & 3 & 2 & 2,50 \\
\hline $\mathbf{7}$ & 3 & 3 & 3 & 2 & 2,75 \\
\hline $\mathbf{8}$ & 3 & 4 & 4 & 3 & 3,50 \\
\hline $\mathbf{9}$ & 3 & 3 & 4 & 3 & 3,25 \\
\hline $\mathbf{1 0}$ & 3 & 3 & 3 & 2 & 2,75 \\
\hline $\mathbf{1 1}$ & 3 & 3 & 4 & 3 & 3,25 \\
\hline $\mathbf{1 2}$ & 3 & 3 & 3 & 2 & 2,75 \\
\hline $\mathbf{1 3}$ & 3 & 3 & 4 & 3 & 3,25 \\
\hline
\end{tabular}
dalam tabel 6 .

Berikut adalah analisa gap current maturity dan expected maturity domain APO yang terangkum

Tabel 6. Analisa GAP Domain APO

\begin{tabular}{|c|l|c|c|c|}
\hline No & \multicolumn{1}{|c|}{ Pertanyaan } & $\begin{array}{c}\text { Current } \\
\text { Maturity }\end{array}$ & $\begin{array}{c}\text { Expect } \\
\text { Maturity }\end{array}$ & $\begin{array}{c}\text { Analisa } \\
\text { Gap }\end{array}$ \\
\hline \hline 1. & $\begin{array}{l}\text { Menurut anda, bagaimana implentasi dan pemeliharan } \\
\text { mekanisme untuk pengelolaan informasi dan penggunaan TI ? }\end{array}$ & 3,00 & 5,00 & 2,00 \\
\hline 2. & $\begin{array}{l}\text { Menurut anda, bagaimana pengelolaan TI dalam mendukung } \\
\text { strategi bisnis yang dilakukan oleh perusahaan saat ini? }\end{array}$ & 3,25 & 5,00 & 1,75 \\
\hline 3. & Menurut anda, bagaimanakah arsitektur perusahaan saat ini? & 2,50 & 5,00 & 2,50 \\
\hline 4. & $\begin{array}{l}\text { Menurut anda, bagaimana pengelolaan SDM pada perusahaan } \\
\text { saat ini? }\end{array}$ & 2,75 & 5,00 & 2,25 \\
\hline 5. & $\begin{array}{l}\text { Menurut anda, bagaimana hubungan TI dengan proses bisnis } \\
\text { yang telah berjalan saat ini? }\end{array}$ & 3,50 & 5,00 & 1,50 \\
\hline 6. & Bagaimana keselarasan TI terhadap kebutuhan bisnis anda? & 3,25 & 5,00 & 1,75 \\
\hline 7. & $\begin{array}{l}\text { Menurut anda, bagaimana peranan TI dalam pengelolaan } \\
\text { pemasok? }\end{array}$ & 2,75 & 5,00 & 2,25 \\
\hline 8. & $\begin{array}{l}\text { Menurut anda, bagaimana organisasi meningkatkan layanan } \\
\text { kulitas TI? }\end{array}$ & 3,25 & 5,00 & 1,75 \\
\hline 9. & Bagaimana pengelolaan risiko yang dilakukan oleh TI? & 2,75 & 5,00 & 2,25 \\
\hline 10. & Bagaimanakah pengelolaan keamanan TI yang ada? & 3,25 & 5,00 & 1,75 \\
\hline & Rata-rata & $\mathbf{3 , 0}$ & $\mathbf{5 , 0 0}$ & \\
\hline
\end{tabular}

Analisa Gap antara Current Maturity dan Expected Maturity ditampilkan melalui grafik yang dapat dilihat pada gambar 3 . 


\section{Domain APO}

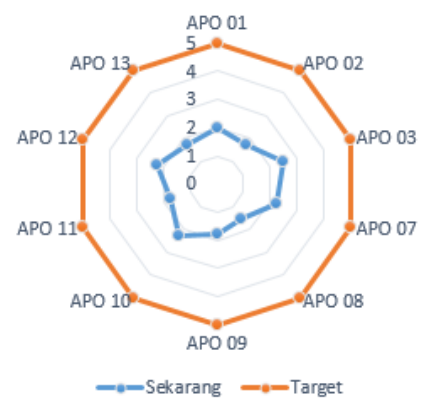

Gambar 3. Tampilan Grafik Current dan Target Maturity Level Domain APO

\subsection{Domain BAI (Build, Acquire and Operate)}

Dari penyebaran kuisioner yang dilakukan untuk menilai Domain BAI, didapatkan rekap hasil kuisioner yang dapat dilihat pada tabel 7.

Tabel 7. Perhitungan Rata-Rata Domain BAI

\begin{tabular}{|c|c|c|c|c|l|}
\hline BAI & Responden 1 & Responden 2 & Responden 3 & Responden 4 & Rata-rata \\
\hline $\mathbf{1}$ & 3 & 3 & 4 & 2 & 3,00 \\
\hline $\mathbf{2}$ & 3 & 3 & 4 & 4 & 3,50 \\
\hline $\mathbf{3}$ & 3 & 3 & 4 & 3 & 3,25 \\
\hline $\mathbf{4}$ & 3 & 3 & 4 & 3 & 3,25 \\
\hline $\mathbf{5}$ & 3 & 2 & 4 & 3 & 3,00 \\
\hline $\mathbf{6}$ & 3 & 3 & 4 & 3 & 3,25 \\
\hline $\mathbf{7}$ & 3 & 3 & 3 & 2 & 2,75 \\
\hline $\mathbf{1 0}$ & 3 & 3 & 3 & 3 & 3,00 \\
\hline
\end{tabular}

Berikut adalah analisa gap current maturity dan expected maturity domain BAI yang terangkum pada tabel 8 .

Tabel 8. Analisa Gap Domain BAI

\begin{tabular}{|c|l|c|c|c|}
\hline No & \multicolumn{1}{|c|}{ Pertanyaan } & $\begin{array}{c}\text { Current } \\
\text { Maturity }\end{array}$ & $\begin{array}{c}\text { Expexted } \\
\text { Maturity }\end{array}$ & $\begin{array}{c}\text { Analisa } \\
\text { Gap }\end{array}$ \\
\hline \hline 1 & $\begin{array}{l}\text { Bagaimana pengelolaan program yang telah berjalan saat } \\
\text { ini? }\end{array}$ & 3,00 & 5,00 & 2,00 \\
\hline 2 & $\begin{array}{l}\text { Bagaimana identifikasi dan analisis kebutuhan program agar } \\
\text { sesuai dengan strategi perusahaan? }\end{array}$ & 3,50 & 5,00 & 1,50 \\
\hline 3 & $\begin{array}{l}\text { Bagaimanakah identifikasi solusi atas masalah yang } \\
\text { dihadapi dalam pengelolaan sistem? }\end{array}$ & 3,25 & 5,00 & 1,75 \\
\hline 4 & $\begin{array}{l}\text { Bagaimanakah pengelolaan ketersediaan dan kapasitas } \\
\text { layanan TI terhadap kebutuhan bisnis saat ini? }\end{array}$ & 3,25 & 5,00 & 1,75 \\
\hline 5 & $\begin{array}{l}\text { Bagaimanakah pengelolaan perubahan organisasi yang telah } \\
\text { berjalan? }\end{array}$ & 3,00 & 5,00 & 2,00 \\
\hline 6 & $\begin{array}{l}\text { Bagaimanakah pengelolaan perubahan teknologi informasi } \\
\text { yang telah berjalan? }\end{array}$ & 3,25 & 5,00 & 1,75 \\
\hline 7 & $\begin{array}{l}\text { Bagaimanakah kemampuan perusahaan dalam mengelola } \\
\text { transisi setelah perubahan pada sistem perusahaan? }\end{array}$ & 2,75 & 5,00 & 2,25 \\
\hline 8 & $\begin{array}{l}\text { Apakah konfigurasi TI yang ada sudah dapat melayani dan } \\
\text { memenuhi sesuai kebutuhan perusahaan? }\end{array}$ & 3,00 & 5,00 & 2,00 \\
\hline & Rata-rata & $\mathbf{3 , 1 0}$ & $\mathbf{5 , 0 0}$ & \\
\hline
\end{tabular}

Analisa Gap antara Current Maturity dan Expected Maturity ditampilkan melalui grafik yang dapat dilihat pada gambar 4.3 


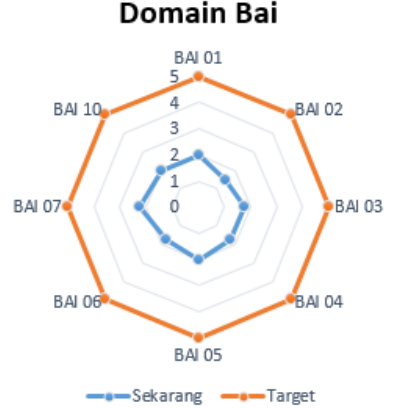

Gambar 4. 1 Tampilan Grafik Current dan Target Maturity Level Domain BAI

3.6 Domain DSS (Deliver, Service and Support)

Dari penyebaran kuisioner yang dilakukan untuk menilai Domain DSS, didapatkan rekap hasil kuisioner dapat dilihat pada tabel 7.

Tabel 7. Perhitungan Rata-Rata Domain DSS

\begin{tabular}{|c|c|c|c|c|c|}
\hline DSS & Responden 1 & Responden 2 & Responden 3 & Responden 4 & Rata-rata \\
\hline $\mathbf{1}$ & 3 & 3 & 4 & 3 & 3,25 \\
\hline $\mathbf{2}$ & 3 & 2 & 3 & 2 & 2,50 \\
\hline $\mathbf{3}$ & 3 & 4 & 4 & 2 & 3,25 \\
\hline $\mathbf{4}$ & 3 & 3 & 4 & 4 & 3,50 \\
\hline $\mathbf{5}$ & 3 & 3 & 3 & 2 & 2,75 \\
\hline $\mathbf{6}$ & 3 & 3 & 4 & 3 & 3,25 \\
\hline
\end{tabular}

Berikut adalah analisa gap current maturity dan expected maturity domain DSS yang terangkum pada tabel 8.

Tabel 8. Analisa GAP Domain DSS

\begin{tabular}{|c|l|c|c|c|}
\hline No & \multicolumn{1}{|c|}{ Pertanyaan } & $\begin{array}{c}\text { Current } \\
\text { Maturity }\end{array}$ & $\begin{array}{c}\text { Expected } \\
\text { Maturity }\end{array}$ & $\begin{array}{c}\text { Analisa } \\
\text { Gap }\end{array}$ \\
\hline \hline 1. & $\begin{array}{l}\text { Bagaimanakah implementasi prosedur operasi TI yang } \\
\text { berjalan saat ini? }\end{array}$ & 3,25 & 5,00 & 1,75 \\
\hline 2. & $\begin{array}{l}\text { Bagaimanakah pengelolaan permintaan \& insiden } \\
\text { layanan yang terjadi? }\end{array}$ & 2,00 & 5,00 & 3,00 \\
\hline 3. & $\begin{array}{l}\text { Bagaimankah pengelolaan permasalahan TI dan } \\
\text { keamanan TI yang ada pada perusahaan? }\end{array}$ & 3,25 & 5,00 & 1,75 \\
\hline 4. & $\begin{array}{l}\text { Bagaimana perusahaan membangun rencana TI yang } \\
\text { berkelanjutan untuk mengurangi resiko yang mungkin } \\
\text { dapat terjadi? }\end{array}$ & 3,50 & 5,00 & 1,50 \\
\hline 5. & $\begin{array}{l}\text { Bagaimana pengelolaan layanan keamanan TI dan } \\
\text { menjamin kerahasiaan data untuk bisnis? }\end{array}$ & 3,00 & 5,00 & 2,00 \\
\hline 6. & $\begin{array}{l}\text { Bagaimanakah perusahaan mengevaluasi kontrol atas } \\
\text { proses bisnis yang ada? }\end{array}$ & 3,25 & 5,00 & 1,75 \\
\hline \multicolumn{2}{|r|}{ Rata-rata } & $\mathbf{3 , 0 0}$ & $\mathbf{5 , 0 0}$ & \\
\hline
\end{tabular}

Analisa Gap antara Current Maturity dan Expected Maturity ditampilkan melalui grafik yang dapat dilihat pada gambar 4.

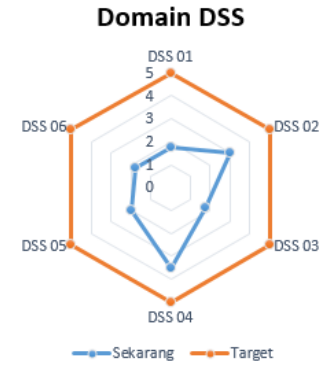

Gambar 4. Tampilan Grafik Current dan Target Maturity Level Domain DSS

\subsection{Domain MEA (Monitor, Evaluate, and Asses)}

Dari penyebaran kuisioner yang dilakukan untuk menilai Domain MEA, didapatkan rekap hasil kuisioner dapat dilihat pada tabel 9. 
Tabel 9. Perhitungan Rata-Rata Domain MEA

\begin{tabular}{|c|c|c|c|c|c|}
\hline MEA & Responden 1 & Responden 2 & Responden 3 & Responden 4 & Rata-rata \\
\hline $\mathbf{1}$ & 3 & 3 & 4 & 3 & 3,25 \\
\hline $\mathbf{2}$ & 3 & 3 & 4 & 3 & 3,25 \\
\hline $\mathbf{3}$ & 3 & 3 & 4 & 2 & 3,00 \\
\hline
\end{tabular}

Berikut adalah analisa gap current maturity dan expected maturity domain MEA yang terangkum pada tabel 10 .

Tabel 10. Analisa GAP Domain MEA

\begin{tabular}{|c|l|c|c|c|}
\hline No & \multicolumn{1}{|c|}{ Pertanyaan } & $\begin{array}{c}\text { Current } \\
\text { Maturity }\end{array}$ & $\begin{array}{c}\text { Expected } \\
\text { Maturity }\end{array}$ & $\begin{array}{c}\text { Analisa } \\
\text { Gap }\end{array}$ \\
\hline \hline 1. & $\begin{array}{l}\text { Apakah perusahaan mampu memantau } \\
\text { kinerja,peforma dan kesesuaian TI dalam bisnis? }\end{array}$ & 3,25 & 5,00 & 1,75 \\
\hline 2. & $\begin{array}{l}\text { Apakah perusahaan mampu mengevaluasi dan } \\
\text { menilai sistem pengendalian internal? }\end{array}$ & 3,25 & 5,00 & 1,75 \\
\hline 3. & $\begin{array}{l}\text { Apakah perusahaan mampu mengevaluasi dan } \\
\text { menilai kepatuhan dengan persyaratan eksternal? }\end{array}$ & 3,00 & 5,00 & 2,00 \\
\hline & Rata-rata & $\mathbf{3 , 1 7}$ & $\mathbf{5 , 0 0}$ & \\
\hline
\end{tabular}

Analisa Gap antara Current Maturity dan Expected Maturity ditampilkan melalui grafik yang dapat dilihat pada gambar 5 .

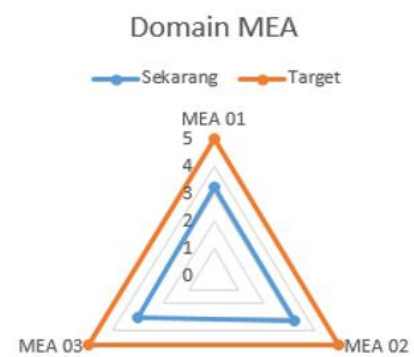

\subsection{Rekomendasi Perbaikan}

Gambar 2. Tampilan Grafik Current dan Target Maturity Level Domain MEA

Tahap rekomendasi perbaikan sudah pada proses output. Sudah pada tahap pemberian rekomendasi merujuk pada hasil dari analisis kuisioner COBIT 5, yang kemudian rekomendasi perbaikan ini adalah saran saran perbaikan yang sesuai dengan penjelasan COBIT 5 untuk diberikan kepada Gelato Secrets.

Domain EDM (Evaluate, Direct and Monitor)

1) EDM01 - Memastikan pengaturan dan tata kelola TI

Saat ini, proses EDM01 berada pada level 3. Untuk memenuhi harapan manajemen, harus dilakukan evaluasi berkala secara konsisten dan terjadwal, sehingga tata kelola TI yang ada mampu mengimbangi kebutuhan bisnis, proses pelayanan bisnis efektif dan efisien, serta melakukan evaluasi proses strategi IT dalam pengambilan keputusan pengoptimalan TI dalam perusahaan.

2) EDM 02 - Memastikan penyampaian manfaat tata kelola TI

Diperlukan peninjauan nilai atau manfaat dari pengadaan perangkat TI untuk mengetahui seberapa besar manfaat TI dalam proses keseluruhan dalam perusahaan, baik itu pengecekan harian, mingguan, maupun sebulan sekali.

3) EDM 03 - Memastikan optimalisasi risiko

Dengan menggunakan TI sebagai unsur penunjang utama bisnis, tentu saja terdapat risiko - risiko penggunaan TI yang harus diatasi. Sistem yang ada masih kurang mampu menyelesaikan proses bisnis, atau belum memenuhi kebutuhan bisnis. Salah satunya di setiap outlet belum terdapat printer untuk mencetak setiap nota transaksi, agar staff yg bekerja lebih mudah saat closing.

4) EDM 04 - Memastikan optimalisasi sumber daya

Saat ini, level optimalisasi sumber daya berada pada level 3. Untuk memenuhi harapan manajemen yang berada pada level 5, diperlukan adanya pengelolaan manajemen sumber daya manusia. Tidak adanya evaluasi dan pemeliharaan perangkat keras juga menjadi penyebab sumber daya tidak optimal pemanfaatannya. Sehingga diperlukan evaluasi dan pemeliharaan terjadwal terhadap perangkat keras yang ada, yang mampu memperpanjang masa pakai perangkat keras.

5) EDM 05 - Memastikan transparansi informasi kepada pemangku kepentingan 
Peningkatan transparansi antara karyawan, manager dan owner dengan melakukan pertemuan dan rapat koordinasi secara rutin. Melakukan pemeriksaan laporan secara berkala agar setiap informasi yang diterima disetiap divisi akurat dan erta menghindari sebuah pengambilan keputusan yang salah.

Domain APO (Align, Plan and Organize)

1) APO 01 - Mengelola kerangka kerja manajemen TI

Rekomendasi pada subbab ini yaitu menyusun kebijakan standar terhadap pengelolaan TI secara menyeluruh yang mencakup aspek infrastruktur, aspek sistem informasi atau aplikasi, aspek SDM, aspek proses (SOP), serta aspek data dan informasi, sehingga pengelolaan TI di Gelato Secrets menjadi lebih teratur dan terstruktur.

2) APO 02 - Mengelola strategi TI selaras dengan bisnis

Rekomendasi pada subbab ini perusahaan sudah mengelola strategi dengan baik, namun perlu diperhatikan lagi kebutuhan software maupun hardware agar dapat meminimalisir segala kendala yang ada, sehingga bisnis dapat berjalan dengan lancar.

3) APO 03- Mengelola arsitektur perusahaan

Diperlukan sebuah adaptasi sistem informasi yang baru dan juga pelatihan kepada setiap pengguna dengan memberikan arahan dalam menggunaan sistem tersebut. Setiap bidang perlu mengoptimalkan koordinasi tentang teknologi yang digunakan agar selaras dengan arsitektur perusahaan.

4) APO 07 - Mengelola sumber daya manusia

Dengan adanya manajemen SDM, maka perlu dilakukan sebuah evaluasi berkala terhadap SDM yang ada. Melakukan pelatihan penggunaan aplikasi sehingga ketrampilan dan kompetensi karyawan terkait terus meningkat sesuai dengan kebutuhan perusahaan dan proses bisnis dapat berjalan dengan lancar.

5) APO 08 - Memahami hubungan TI dengan bisnis

Untuk mencapai level maturity yang diharapkan perusahaan, maka perlu dilakukan sebuah pelatihan atau sosialisasi tentang pentingnya TI di setiap proses bisnis yang ada, sehinggan TI bisa dimanfaatkan sesuai dengan kebutuhan perusahaan.

6) APO 09 - Menyelaraskan pelayanan TI terkait dengan kebutuhan bisnis

Layanan TI yang ada saat ini, berupa aplikasi Odoo dapat dioptimalkan penggunaannya, dengan dibuatnya sebuah prosedur penggunaan layanan, yang berisi fungsi dan langkah - langkah penggunaan menu - menu pada sistem. Sehingga pengguna mampu mempelajari dan mempergunakan menu - menu yang tersedia untuk memperlancar pelayanan bisnis.

7) APO 10 - Mengelola pemasok

Dalam mengelola pemasok Gelato Secrets perlu menambahkan menu purchase order ataupun menambahkan contact dari pemasok yang ada di dalam aplikasi Odoo.

8) APO 11 - Mengelola kualitas sistem manajemen mutu

Pengelolaan kualitas sistem manajemen sudah cukup baik, namun perusahaan perlu untuk mengutamakan pemenuhan kebutuhan operasional, agar proses bisnis bisa berjalan dengan lancar.

9) APO 12 - Mengelola risiko TI

Pengelolaan risiko di Gelato Secrets masih dalam tahap identifikasi, berupa pengumpulan data proses bisnis berjalan dan analisis risiko yang muncul. Sampai saat ini, telah ditemukan risiko penggunaan TI berupa sistem yang dikembangkan masih memiliki kekurangan dan belum memenuhi kebutuhan organisasi, segala kekurangan pada sistem informasi yang ada perlu untuk dievaluasi agar tidak menghambat proses bisnis yang ada.

10) APO 13 - Mengelola keamanan TI

Mendefinisikan, mengoperasikan dan melakukan pemantauan terhadap sistem pengelolaan keamanan informasi yang sudah cukup baik, untuk mencapai level maturity yang diharapkan maka perusahaan perlu untuk melakukan peningkatan kualitas pengamanan data, baik berupa data elektronik maupun data tertulis, agar semua data dapat terjaga dengan baik.

Domain BAI (Build, Acquire and Operate)

1) BAI 01 - Mengelola program \& proyek

Peningkatan pengelolaan program dilakukan dengan cara memelihara standar untuk pengelolaan program dan proyek terkait kebutuhan, risiko, biaya, jadwal dan mutu.

2) BAI 02 - Menganalisis kebutuhan program selaras dengan strategi perusahaan 
Sebuah analisis kebutuhan program perlu ditingkatkan dengan melakukan analisis kebutuhan program agar program tersebut mampu membantu dalam proses bisnis agar lebih efisien, mengubah sebuah pencatatan manual menjadi terkomputerisasi, serta permintaan pengguna agar lebih diperhatikan dan dievaluasi untuk ditindak lanjuti.

3) BAI 03 - Melakukan pengembangan solusi

Untuk meningkatkan sebuah pengembangan solusi, penanggung jawab TI harus meninjau kembali sebuah solusi pengembangan yang diperlukan pengguna agar proses bisnis berjalan sesuai yang diharapkan perusahaan.

4) BAI 04 - Mengelola Ketersediaan \& Kapasitas

Penanggungjawab TI telah melakukan pengelolaan terhadap ketersediaan, kapasitas layanan dan sumber daya pendukung kebutuhan bisnis sudah cukup baik, perlu dilakukan perbaikan, dan pengembangan sistem agar layanan menjadi lancar, sehingga faktor pendukung maupun penghambat kinerja sistem dapat diketahui.

5) BAI 05 - Mengelola Pemberdayaan Perubahan Organisasi

Rekomendasi pada subbab ini perubahan organisasi dilakukan jika terdapat SDM yang sudah tidak mampu memberikan tanggung jawab di bidangnya, karena kemampuan SDM sangat mempengaruhi proses berjalannya bisnis.

6) BAI 06 - Mengelola perubahan

Melakukan sebuah review perubahan secara berkala agar bisa menindak lanjuti perubahan tersebut dan kesesuaian perubahan terhadap keinginan pemilik dapat diketahui.

7) BAI 07 - Mengelola transisi setelah perubahan

Dalam mengelola transisi setelah perubahan, perusahaan perlu untuk mengantisipasi kinerja,serta siap membantu SDM untuk menyesuaikan diri dengan perubahan.

8) BAI 10- Mengelola konfigurasi

Perusahaan perlu untuk melakukan evaluasi secara berkala untuk mengetahui kekurangan dari aplikasi yang digunakan, menambahkan menu-menu yang kurang pada aplikasi Odoo.

\section{Domain DSS (Deliver, Service and Support)}

1) DSS 01 - Mengevaluasi pengelolaan operasi TI yang telah berjalan

Dalam mengevaluasi operasi TI yang telah berjalan Gelato Secrets perlu melakukan penilaian terhadap infrastruktur yang dimiliki dan dibuatkan dokumentasinya untuk bahan evaluasi kedepannya. Menjaga dan memonitoring infrastruktur dengan baik, karena telah disediakan CCTV namun tidak ada yang mengoperasikannya, lebih baik pegawai diberikan arahan agar selalu melakukan pengecekan terhadap CCTV.

1) DSS02 - Mengelola permintaan dan insiden layanan

Untuk melakukan pengelolaan permintaan dan insiden layanan maka dibuatkan klasifikasi terhadap jenis - jenis layanan dan insiden yang dilayani, membuat sebuah strategi - strategi dalam permintaan layanan dan pemecahan insiden baik dalam bentuk kebijakan ataupun tindakan penanganan langsung seperti sistem.

2) DSS 03 - Mengelola permasalahan

Rekomendasi perbaikan untuk subbab ini dengan mendokumentasikan dan mengalisa kembali laporan masalah yang ada, baik yang sudah terselesaikan maupun yang belum terselesaikan, hal tersebut dapat dilakukan dengan membuat sebuah sistem yang dapat mengetahui jalannya penyelesaian pemecahan masalah yang ada agar dapat dipantau oleh pihak atasan, serta membuat dokumentasi terkait solusi - solusi dalam pemecahan masalah.

3) DSS 04 - Mengelola kontinuitas pelayanan TI

Dalam meningkatkan kontinuitas pelayanan TI rekomendasi yang diberikan yaitu dengan melakukan pengukuran keberlangsungan proses bisnis untuk mengetahui tingkat kematangannya dan kesenjangan proses bisnis, didokumentasikan dan dievaluasi. Evaluasi dilakukan terhadap kebutuhan keberlanjutan proses bisnis yang berlangsung, serta membuat ketetapan ukuran - ukuran untuk pengambangan latihan sumber daya manusia yang dimiliki, dan dipantau keberlangsungannya.

4) DSS 05 - Mengelola layanan keamanan

Pengelolaan ini sudah cukup baik, tetapi perlu dilakukan evaluasi yang dilakukan rutin, minimal tiap sebulan terhadap sistem informasi yang nantinya dikhawatirkan dapat timbul potensi ancaman baru, 
mengukur kualitas sistem keamanan dan hak akses yang diberikan. Serta melakukan evaluasi atau memantau hak akses yang diberikan untuk terjaga dari ancaman - ancaman yang potensial.

5) DSS 06 - Mengevaluasi kontrol atas proses bisnis

Penyelarasan aktivitas kontrol atas proses bisnis dengan tujuan Gelato Secrets sudah berlangsung cukup baik. Akan tetapi perusahaan perlu untuk melakukan pemantauan rutin serta melakukan review permasalahan-permasalahan yang terjadi dalam keberlangsungan prose bisnis, mendokumentasikan dan dievaluasi, lalu menyimpan dengan baik atau mengarsipkan data seperti sumber informasi.

Domain MEA (Monitor, Evaluate and Assess)

1) MEA 01 - Memantau kinerja, performa, dan kesesuaian TI dalam bisnis

Dalam subbab ini, sudah terdapat penetapan monitoring, evaluasi dan pengukuran kinerja serta kesesuaian terhadap penerapan dari aplikasi Odoo, namun karena aplikasi ini masih tergolong baru untuk perusahaan ini maka perusahaan perlu untuk melakukan analisis kebutuhan terhadap proses dan aktivitas yang akan dilakukan terkait dengan penerapan aplikasi Odoo agar penerapan aplikasi dapat berjalan secara optimal.

2) MEA 02 - Memantau, mengevaluasi dan menilai sistem pengendalian internal

Dalam subbab ini, sudah terdapat penetapan monitoring, evaluasi dan pengukuran sistem dari pengendalian internal terhadap penerapan aplikasi Odoo, namun SOP dan aktivitas harus dikelola dengan lebih baik lagi sesuai dengan kebijakan yang telah ditetapkan bersama.

3) MEA 03 - Memantau, mengevaluasi dan menilai kepatuhan dengan persyaratan eksternal

Dalam subbab ini, sudah terdapat penetapan monitoring, evaluasi dan pengukuran kecocokan dalam kebutuhan eksternal/luar dari penerapan aplikasi Odoo. Dilakukan pelatihan dan sosialisasi kepada setiap karyawan secara berkala seiring dengan berkembangnya aplikasi agar karyawan lebih memahami prosedur dari penerapan aplikasi Odoo.

\section{Conclusion}

Proses evaluasi mengahasilkan perhitungan dan hasil wawancara serta kuisioner tentang eveluasi kinerja tata kelola teknologi informasi yang diterapkan pada Gelato Secrets. Teknologi Informasi yang digunakan yaitu aplikasi Odoo. Kesimpulannya bahwa tingkat kapabilitas berada pada level 3,13 yaitu Established Process yang artinya setiap sub domain sudah terdefinisi dan terstandarisasi dengan baik. Hal ini menunjukkan hampir semua proses memenuhi syarat, akan tetapi masih tedapat kelemahan pada sisi perubahan sistem yang disebabkan oleh tidak adanya proses dokumentasi yang memadai. Perusahaan masih harus memenuhi proses level 5 yaitu Optimizing Process dengan cara pelatihan rutin kepada SDM tentang Sistem Informasi yang ada. Selain itu juga memenuhi kebutuhan pengguna seperti menambahkan menu-menu yang dapat mempermudah kelancaran proses bisnis agar dapat memenuhi target perusahaan yang diharapkan, serta melakukan penambahan perangkat Teknologi Informasi yang dibutuhkan perusahaan dalam jumlah yang memadai.

\section{References}

[1] E. Ekowansyah, Y. H. Chrisnanto, Puspita, and N. Sabrina, "Audit Sistem Informasi Akademik Menggunakan COBIT 5 di Universitas Jenderal Achmad Yani,” Pros. Semin. Nas. Komput. dan Inform. 2017 (ISBN 978 - 602 60250 - 1 -2), 2017.

[2] G. Waluyan, A. D. Manuputty, F. Teknologi, I. Universitas, and K. Satya, "Evaluasi Kinerja Tata Kelola TI Terhadap Penerapan Sistem Informasi Starclick Framework COBIT 5 ( Studi Kasus: PT . Telekomunikasi Indonesia , Tbk Semarang )," vol. 02, no. 03, pp. 157-166, 2016.

[3] A. Hakim, H. Saragih, and A. Suharto, "Evaluasi Tata Kelola Teknologi Informasi Dengan Framwork Cobit. 5 Di Kementerian Esdm,” J. Sist. Inf., vol. 10, no. 2, 2014, doi: 10.21609/jsi.v10i2.393.

[4] A. Febriani, "Analisa Dan Pengembangan Tata Kelola Teknologi Informasi (IT Governance) Menggunakan Cobit 5,” J. Ilmu Komput., vol. 6, no. 2, pp. 97-102, 2017, doi: 10.33060/JIK/2017/Vol6.Iss2.68.

[5] K. Devanti, W. Gede, S. Parwita, and I. K. B. Sandika, "Audit Tata Kelola Teknologi Informasi Menggunakan Framework COBIT 5 Pada PT . Bisma Tunas Jaya Sentral,” vol. 2, no. 2, pp. 65-76, 2019.

[6] A. M. Syuhada, "Kajian Perbandingan Cobit 5 dengan Cobit 2019 sebagai Framework Audit Tata Kelola Teknologi Informasi," Syntax Lit.; J. Ilm. Indones. Vol 6 No 1 J. Syntax Lit. J. Ilm. Indones., 2021, doi: 10.36418/syntax-literate.v6i1.2082.

[7] Muchsam, Y., Falahah, F., dkk. 2011. "Penerapan Gap Analysis Pada Pengembangan Sistem Pendukung Keputusan Penilaian Kinerja Karyawan (Studi Kasus PT.XYZ)". Seminar Nasional Aplikasi Teknologi Informasi (SNATI), 2011(Snati), 17-18. 